\title{
COVID-19: đcuál es el rol ético del odontólogo ante esta pandemia?
}

\section{COVID-19: what is the ethical role of the dentist in face of this pandemic?}

\author{
Mariana Isabel Dos Santos Rodríguez*
}

\section{RESUMEN}

Introducción: Para un buen profesional de la odontología es necesaria la ética en todas las actividades que realice. La ética establece lo que es y debe ser, buscando siempre el bien y no hacer el mal o causar daño, y el odontólogo debe tener una serie de cualidades y aptitudes con el fin de llevar a cabo todo el tratamiento que amerite el paciente de manera correcta, honesta y responsable sin escatimar esfuerzos para devolverle su salud oral. La COVID-19 es una enfermedad que se ha convertido en pandemia y está afectando al mundo de manera importante. Entre los más afectados se encuentran los profesionales de la salud que arriesgan sus vidas por sanar al enfermo. Dada la situación actual, a los odontólogos se les presenta la duda si atender a sus pacientes en este periodo cumple o no con los principios éticos de la profesión. Objetivo: El objetivo del presente artículo fue realizar una revisión sistemática de la literatura con el fin de identificar el rol bioético del odontólogo ante la pandemia de COVID-19. Material y métodos: Para realizar la recolección de la literatura se compilaron artículos de diferentes bases de datos: PubMed, Cochrane, Nature y Lilacs producidos entre los años 2012 y 2020 con las palabras clave: ética, odontología, pandemia, COVID-19 y bioética en los idiomas español, inglés y portugués. Resultados: Se localizaron 70 artículos, de los cuales se escogieron finalmente 10 correspondientes a los criterios de búsqueda. Los artículos presentaron homogeneidad sobre el rol del odontólogo en la situación actual y coinciden en la búsqueda de alternativas y métodos de atención lo más seguras posibles, dando prioridad a quienes requieren atención de urgencias.

Palabras clave: Ética, bioética, odontología, COVID-19, pandemia.

\section{ABSTRACT}

Introduction: For a good dental professional, ethics is necessary in all the activities performed. Ethics stablish what is and what should be, always looking for the good and not the bad, the dentist should have a series of qualities and skills in order to perform every treatment that the patient needs in a correct, honest and responsible way without sparing efforts to give them back their oral health. COVID-19 is a disease that has converted into a pandemic affecting the world in an important manner. And, between the most affected are the health providers and professionals that risk their lives to heal the people suffering this disease. Given the current situation, dentists have been found in doubt regarding if treating their patients in this period meets or not the ethical principles of their profession. Objective: The objective of this article is to perform a systematic review of literature in order to identify the bioethics role of the dentist in face of the COVID-19 pandemic. Material and methods: To carry out the collection of literature the procedure included compiling different articles from the databases: PubMed, Cochrane, Nature, and Lilacs produced between the years of 2012 and 2020 with the key words: ethics, dentistry, pandemic, COVID-19, bioethics in the languages of Spanish, English and Portuguese. Results: 70 papers were located from which only 10 were chosen meeting the searching criteria. The papers presented homogenous results about the role of dentists in the current situation and the all agree in the search of alternatives and methods of care that are as secure as possible, giving priority to those who are in need of urgent care.

Keywords: Ethics, bioethics, dentistry, COVID-19, pandemic.

\section{www medigraphic.org.mx} * Estudiante de Licenciatura Médico Cirujano Dentista. Facultad de Ciencias de la Salud. Universidad Anáhuac México. Estado de México,
México. https://orcid.org/0000-0002-2784-6044.
Recibido: 18 de marzo de 2021. Aceptado: 23 de noviembre de 2021 .
Citar como: Dos Santos RMI. COVID-19: icuál es el rol ético del odontólogo ante esta pandemia? Rev ADM. 2021; 78 (6): 350-355. https://dx.doi.
org/10.35366/102977 


\section{INTRODUCCIÓN}

$E^{\prime}$ mundo se encuentra actualmente ante una crisis humanitaria que no se puede comparar con ninguna otra vivida en tiempos recientes: el coronavirus 2019, también conocido como COVID-19. La magnitud de esta pandemia está alterando nuestro día a día, afectando muchas actividades como nunca antes habíamos visto. El sector sanitario no se escapa de esta realidad y se está viendo gravemente impactado en estos momentos de angustia e incertidumbre. Los médicos y enfermeros no se detienen, tampoco los trabajadores esenciales, pero ¿cuál debe ser el rol del odontólogo durante una pandemia altamente contagiosa y que cobra la vida de miles de personas?

A través de los siglos han existido diferentes pandemias que, lamentablemente, han cobrado la vida de muchas personas y ha expuesto al personal de la salud a altos riesgos de contagio. Es poner en peligro la vida por darle la oportunidad al enfermo de sanar y recuperarse. El COVID-19, debido a su facilidad de contagio, el cual ocurre cuando el virus entra en contacto con las membranas mucosas orales, nasales y oculares, que pone en riesgo la vida de muchos sin distinción alguna, está siendo hoy una gran adversidad para el sistema sanitario.

El COVID-19 es una enfermedad derivada de un nuevo coronavirus, siendo el SARS-CoV-2 (síndrome respiratorio agudo coronavirus 2) el principal factor etiológico. EI SARS-CoV-2 se identificó por primera vez en la ciudad Wuhan, China en diciembre de 2019, y rápidamente se esparció a nivel global, siendo declarada la enfermedad COVID-19 como pandemia y como emergencia sanitaria de preocupación internacional (PHEIC por sus siglas en inglés) por la Organización Mundial de la Salud (OMS) el 11 de marzo de 2020, generando un grave problema de salud pública mundial.

Ante tal globalización del COVID-19, el trabajador sanitario se ha encontrado con barreras difíciles de sobrepasar sin poder detener sus actividades, esto unido al poco conocimiento acerca de la enfermedad que ha provocado el aumento exponencial de los contagios y ha cobrado la vida de personal sanitario, ya que el control de infecciones ante este nuevo coronavirus en su inicio y propagación no era claro.

En un estudio publicado en marzo de este año por el New York Times ${ }^{1}$ ha surgido información sobre las profesiones que tienen más probabilidad de contagio ante cualquier enfermedad, y en especial del COVID-19, y no es una sorpresa para nadie que los odontólogos se encuentren en el primer lugar de estos datos. Trabajar directamente con pacientes de una forma tan cercana y con la cavidad oral es un proceso de alta probabilidad de contagio de muchas enfermedades. En consecuencia, el objetivo de este estudio fue realizar una revisión sistemática de la literatura con el fin de identificar el rol bioético del odontólogo ante la pandemia del COVID-19.

\section{MATERIAL Y MÉTODOS}

Se realizó una revisión sistemática de la literatura relacionada a la ética en la odontología y el rol del odontólogo durante una pandemia. Para realizar la recolección de la literatura se recopilaron artículos de diferentes bases de datos: PubMed, Cochrane, Nature y Lilacs producidos entre los años 2012 y 2020.

Para la recolección de datos se utilizaron las palabras clave de búsqueda en idioma español: ética, odontología, pandemia, COVID-19, bioética. De igual forma, se realizó la búsqueda con las palabras en idioma inglés: ethics, dentistry, pandemic, COVID-19, bioethics. Por último, se incluyeron en la búsqueda su traducción al idioma portugués: ética, estomatología, pandemia, COVID-19, bioética.

La selección de los artículos se realizó con base en los siguientes criterios de inclusión: idioma inglés, español y portugués, artículos de revisión sobre ética y bioética en odontología así como artículos sobre el rol de la odontología durante el COVID-19 y recomendaciones al respecto publicados entre los años 2012 y 2020. Por otro lado, los criterios de exclusión en la investigación fueron: estudios de años anteriores a 2012, artículos fuente no indexados o de relevancia odontológica.

Todos los artículos estudiados fueron evaluados de manera individual e independiente. De los 70 artículos encontrados en las bases de datos, se excluyeron 20 artículos por no ser de carácter bioético, además se redujeron 40 artículos por no ser del área odontológica. Al final del tamizaje quedaron 10 artículos como instrumento de la revisión sistemática de la bibliografía (Figura 1).

El objetivo final de estos artículos se centró en el reconocimiento del rol de la odontología durante una pandemia y cómo practicar la profesión bajo su código de ética en estas circunstancias.

\section{RESULTADOS}

\section{Ética}

Elster $\mathrm{N}$ y Elliott $\mathrm{T}^{2}$ definen la ética como estándares bien fundados sobre lo que está bien o mal, que prescribe a 
los humanos lo que deberían hacer según sus derechos, deberes, entre otros. Con esto llegan a concluir que se trata de un tema subjetivo sin blancos o negros y que tiende a tener una distinción en cada persona.

Por su parte, Camargo F y colaboradores ${ }^{3}$ definen la ética como «...rama de la filosofía que estudia la moralidad, una especie de «ciencia» de la moral, la reflexión sobre lo que es correcto e incorrecto» y llegan a la conclusión de que se trata de un tema que tiene la finalidad de esclarecer y sistematizar las bases del hecho moral. En su estudio llegan a la conclusión de que los odontólogos estudiados tienen una noción de la ética, pero aun así encuentran dificultades para solucionar problemas o tomar decisiones éticas en la práctica del día a día.

\section{Bioética}

Orellana Centeno y Guerrero Sotelo ${ }^{4}$ definen la bioética como una disciplina de carácter filosófico que deriva de la ética que «...se encarga de la reflexión en general sobre los valores, las normas, las acciones morales, y especialmente los hechos médicos y los derivados de las tecnociencias». Además explican que la bioética es interdisciplinaria, humanista y plural. En ella se logra entonces incluir la odontología como ciencia de la bioética. Y llegan a la conclusión de que «la bioética surge como una respuesta a la necesidad de crear nuevos valores en los profesionales que pudieran enfrentar los cambios que la nueva sociedad va introduciendo».

\section{Ética en odontología}

La odontología se rige, como cualquier otra profesión médica, por los principios de la ética, Naidoo $S^{5}$ explica en su artículo que las enfermedades orales se encuentran entre las más prevalentes en el mundo y que el rol del odontólogo es esencial para cumplir con las necesidades de salud oral del mundo. La ética en odontología no es sólo aplicable en la práctica clínica, sino que también debe regir y considerar cuándo se practica ésta en la salud pública, la educación y la investigación. Menciona que la enseñanza de la ética en las escuelas de odontología debe ser efectiva. Valores como dignidad, derechos humanos, respeto a la autonomía y vulnerabilidad son de suma importancia cuando tratamos el tema de las decisiones éticas y morales, y que éstos en conjunto con los principios de la ética y protección deben ser tomados en cuenta por los profesionales de la salud oral, elevando su práctica a la enseñanza a sus comunidades. Asimismo, resalta que el principio de la justicia se aplica cuando los profesionales de la salud utilizan los recursos de la epidemiología y riesgo social para detectar a los más vulnerables.

\section{Diferencia entre ética y ley}

En su artículo Elster $\mathrm{N}$ y Elliott T estudiaron las implicaciones y las diferencias entre la ley y la ética. Tomando en consideración que este tema tiende a ser de conflicto, explican que la ética es «...más subjetiva que la ley y en ella no existen claros y obscuros», mientras que la ley implica más bien estándares sobre los cuales se espera que las personas se toleren, y se aplican con un bien o mal a todas las personas sin distinción individual. Estos autores llegan a la conclusión de que debe existir un balance entre ambos rubros tomando en consideración que la ley puede o no ser ética, pero la ética no puede ser ley.

\section{Ética, COVID-19 y odontología}

Cohen DF y colaboradores ${ }^{6}$ en su artículo titulado Ethical practice during the COVID-19 pandemic comentan que si bien el documento sobre principios de la ética y código de conducta profesional de la American Dental Association (ADA) es una guía muy útil, la emergencia humanitaria que está ocurriendo está por encima de cualquier consideración y que las decisiones y obligaciones éticas deben cambiar. Explican que la guía dice de manera explícita que el beneficio del paciente es la meta principal, lo que puede llevar a muchas confusiones durante este periodo de emergencia en salud. Es claro que los principios de la ética de «no maleficencia», «beneficencia», «justicia» son esenciales en cualquier práctica odontológica; sin embargo, restringir y suspender algunos, si no la mayoría de los procedimientos que estaban en los planes de la consulta, es parte del deber del profesional proteger a su comunidad de las complicaciones que el COVID-19 desencadena. Muchas dudas vienen relacionadas al cumplimiento de estos principios, pero resumen que protegiéndonos y usando equipos de protección adecuados nos ayuda a cumplir con el principio de la beneficencia buscando el bien del paciente; limitar los pacientes a urgencias nos ayuda a disminuir la posibilidad de infecciones cruzadas cumpliendo con el principio de la no maleficencia. Sin embargo, resaltan que el principio que más dudas ha levantado es el principio de la justicia, ya que debemos atender a todos por igual, pero también destacan que en una situación como la que se vive actualmente se deben hacer cambios y priorizar únicamente a aquellos pacientes que se encuentren en una situación de inestabilidad y que 
no se pueden remitir o dejar de atender, ya que pone en riesgo su bienestar o inclusive su vida.

En su artículo Herazo Acuña $B^{7}$ explica la importancia y relevancia de la aplicación de los principios éticos en momentos de crisis. Comenta que el principio ético fundamental de siempre hacer el bien y nunca el mal o causar daño es aplicable a todos los profesionales de la salud en cualquier situación y no sólo en momentos de calamidad pública como es el COVID-19. Asimismo, considera que los odontólogos están comprometidos a seguir las bases de la ética haciendo el bien y cuidando de ellos mismos y de sus pacientes con métodos severos de bioseguridad, asepsia y antisepsia. Además aclara que no deben sentirse perjudicados ni que están perjudicando a los demás al dejar de atenderles porque «...por encima de su bien y beneficio personal está el de su comunidad» considerando que la atención sólo debe ser de urgencias.

Coulthard $\mathrm{P}^{8}$ expresa en su artículo la importancia de las decisiones morales en la odontología en esta época de pandemia y señala que si bien el equipo odontológico sabe y está completamente familiarizado con los procedimientos de control de infecciones, no debería exponerse a riesgos innecesarios, sobre todo cuando se trata de tratamientos electivos y no urgentes.

Himmelberger $L^{9}$ presenta en su artículo las obligaciones de un dentista cuando se trata de una situación en la que no puede proveer atención como en el caso del COVID-19. En éste explica que la responsabilidad del odontólogo ante pacientes que pueden sufrir un riesgo, es tomar acción para proteger a estos pacientes. Por otra parte, menciona que existe la obligación de atender urgencias ante cualquier situación considerando que una urgencia puede llevar a poner en riesgo la vida de los pacientes.

Por su parte, Spagnoulo y colaboradore ${ }^{10}$ refieren que la odontología es una profesión de altísimo nivel de contagio, ya que se trabaja con una cercanía a la zona de contagio muy elevada. Asimismo, explican que se ha sugerido a los odontólogos tomar medidas de precaución y protección personal; sin embargo, la reducción de la atención sólo a casos que son esenciales o urgentes debe ser tomada en cuenta y debe ser obligatoria.

Kumar y Kirti ${ }^{11}$ hacen referencia en su artículo a la cirugía maxilofacial y ya que ésta es una de las especialidades más recurridas para tratamiento de urgencias, se han visto en la necesidad de tomar decisiones para el cuidado de sus pacientes, de ellos mismos y del personal de los hospitales en los que se encuentran. Además, explican que si bien los pacientes necesitan ciertos tratamientos para mejorar su calidad de vida, la decisión de realizarla o no se va a ver afectada por la situación actual. Al ser una especialidad que no puede dejar de atender traumatismos e infecciones de gravedad, se ven en la necesidad de llevar a cabo consultas por videollamada y tomar las decisiones de ver al paciente en persona si realmente no es posible resolverlo en casa. Al igual, consideran y definen, en conjunto con la red mundial de médicos de los campos de la cirugía oral, facial y maxilofacial (AO CMF) y los Centros para el Control y Prevención de Enfermedades de los Estados Unidos (CDC), que la atención e intervención del cirujano maxilofacial se ve limitada únicamente a traumatismos, manejo inmediato y emergente de vías aéreas, abscesos que necesiten drenaje y procedimientos oncológicos de urgencia. Concluyen en su artículo que la situación del COVID-19 continúa y que si los odontólogos no son requeridos como urgencia, no se deben exponer ellos ni sus pacientes y personal a riesgos innecesarios.

\section{DISCUSIÓN}

El COVID-19 está dando un giro a la vida de todos y la odontología no es la excepción. En los momentos de incertidumbre que se viven actualmente hay que saber cuándo es oportuno atender a un paciente y cuándo no, ya que finalmente son decisiones que se relacionan con hacer el bien o el mal, teniendo como base la ética.

Elster $\mathrm{N}$ y Elliott $\mathrm{T}^{2}$ en su artículo presentan de una manera bastante sencilla el término ética y su diferencia con la ley. Muchos profesionales en las circunstancias de hoy se sienten obligados a atender a sus pacientes pensando que existe una implicación legal en dejar los tratamientos en pausa o que no es ético, y no hacerlo puede llevarlos a una demanda o reclamación. La ley y la ética, si bien se relacionan, son distintas y debe existir un balance entre las mismas. En la situación de emergencia actual la ética se centra en evitar la exposición del paciente ante un posible contagio, por lo que llevar a cabo un tratamiento que no sea de urgencia sin las medidas de higiene $y$ protección correctas puede llevar al contagio del paciente y de ahí a problemas de salud mayores. Esto va de la mano con lo que explican Camargo $\mathrm{F}$ y colaboradores. Esencialmente la ética representa las decisiones morales, que en conjunto, deben ir centradas en el bienestar de la persona, en saber diferenciar el bien y el mal evitando a toda costa ocasionar un daño. Conocer esto nos lleva a concluir de manera clara que durante esta pandemia del COVID-19 atender a pacientes no urgentes puede conducir a un daño más que a un bien. Todo aquél que esté estable y no presente complicaciones no necesita 
atención inmediata, evitando así la exposición al virus y sus repercusiones.

Por su parte Orellana Centeno y Guerrero Sotelo hacen hincapié en que la bioética, si bien es una rama de la ética, es aquélla que se relaciona directamente con la rama médica y que dispone a su vez de principios dirigidos en especial al personal, educación e investigación de carácter médico. La bioética enseña que los odontólogos tienen la obligación de cumplir las medidas sanitarias y de protección personal y del paciente. Actualmente se vuelve muy complicado poder cumplir con los estrictos protocolos de protección sanitaria al 100\%, ya sea por la escasez de insumos por su alta demanda o porque es difícil garantizar que el ambiente, instrumental o material se encuentran completamente libres de una carga viral de alto grado de contagio. Por estas razones se debe considerar postergar los tratamientos no indispensables y así destinar los insumos que se poseen a la atención de urgencias, evitar exponer el material a múltiples usos y prevenir que aerosoles virales e incluso goteos sean esparcidos, que en odontología están directamente relacionados con las áreas de mayor contagio: la cavidad oral y la saliva.

El artículo de Nairo S y el de Coulthard P coinciden en que la odontología debe siempre seguir los principios de la ética y llegan a concluir y coincidir en que el beneficio mayor del paciente debe ir por delante de cualquier situación, demostrando los valores éticos a la comunidad y cumpliendo con lo que se debe y a lo que está obligado. En esta situación el bien mayor del paciente es directamente proporcional a su protección y cuidado. Si el paciente así lo requiere y su vida está en riesgo, el contagio pasa a ser el segundo beneficio y es por ello que la atención de urgencias es necesaria, pero de no ser así, la COVID-19 es el mayor riesgo que hasta el día de hoy un paciente puede sufrir y su protección está primero. Lo mismo se explica en el artículo de Spagnoulo y colaboradores, quienes consideran que debido a la gran cercanía que existe entre el odontólogo y su paciente durante un procedimiento, la probabilidad de contagiar o ser contagiados es muy elevada. Además, como se mencionó anteriormente sobre los estudios recientes publicados por el New York Times, el odontólogo es el profesional en mayor riesgo de contagio de cualquier enfermedad, por lo que es esencial siempre tomar todas las precauciones sanitarias necesarias, cuidando de la salud propia, pero sobre todo cuidando de la salud del paciente, ya que éticamente es la obligación del personal de salud.

Kumar y Kirti por su parte dan un ejemplo claro del personal de salud en el área odontológica que se está necesitando en estos momentos de emergencia sanitaria, y dan a conocer las medidas que se toman ante la situación para poder llevar un mejor control de los pacientes y continuar la labor dentro de las más óptimas condiciones posibles. Explican que la forma más ética de colaborar con la protección de los pacientes y del personal sanitario es mediante videollamadas, que pueden ayudar a diagnosticar si es una urgencia que debe ser atendida de inmediato o si hay alguna medida terapéutica que el paciente pueda llevar a cabo desde su hogar para mantenerse estable. Así se evita que salgan de casa y exponerse a un hospital, considerando que se trate de un procedimiento quirúrgico. De esta manera el odontólogo puede seguir su labor y, si bien no es igual a una exploración física, una buena anamnesis puede ayudar mucho en estos casos.

Por último, el artículo de Cohen DF y colaboradores y el artículo de Herazo Acuña B coinciden en que la ética es un tema esencial en estos momentos bajo las circunstancias que se viven con la pandemia de COVID-19. Herazo Acuña $B$ resalta que la finalidad ética de hacer el bien debe verse reflejada en todos los seres humanos en cualquier situación y para los odontólogos el cuidar a su comunidad pasa a ser más importante que el beneficio propio. Esta afirmación lleva a analizar que si bien los odontólogos deben tomar acción por su comunidad suspendiendo casos electivos, también se ven en la obligación de enseñar a su comunidad la importancia de quedarse en sus hogares y respetar el distanciamiento social para evitar la rápida propagación del

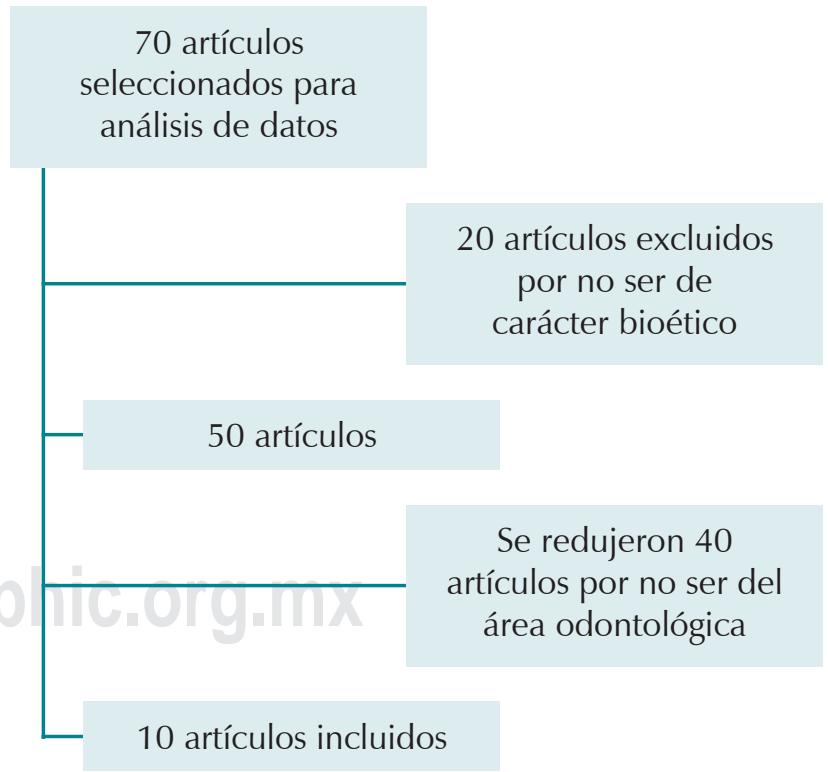

Figura 1: Diagrama de flujo del proceso de selección de los artículos para la revisión bibliográfica. 
virus. Por otro lado, Cohen DF expone en su artículo Ethical practice during the COVID-19 pandemic, que si bien son firmes las bases que se deben llevar a cabo como obligación ética profesional, en momentos de calamidades surgen muchas dudas, ya que no está claro cómo actuar en este tipo de situación. Cohen explica que la preocupación mayor se ve reflejada en cómo interpretar estos principios propuestos en la situación actual y reflexiona que son perfectamente aplicables al periodo de cuarentena. El «principio de la beneficencia» que busca el bien de los demás, se cumple siguiendo las medidas de seguridad sanitaria, utilizando la indumentaria de protección recomendada en caso de pandemia y evitando el contacto con personas o pacientes que no necesiten atención inmediata. El «principio de la no maleficencia», es decir, no hacer el mal o daño a los demás se observa cuando se reduce el número de pacientes a atender dando prioridad a las emergencias y manteniendo el espacio e instrumental libres de contacto con personas ajenas al procedimiento odontológico que se está realizando, ya que éstas pueden ser portadoras del virus. Postergar los tratamientos electivos ayuda a ser más eficientes en el uso de las reservas de material de protección personal y se evita exponer el material e instrumental odontológico a más personas, ya que por más cuidados que nos aseguremos en tener en el proceso de desinfección y esterilización de los mismos, no existe garantía de una protección completa ante un virus altamente contagioso y aún impredecible. Por último, menciona que el «principio de la justicia» que busca atender a todos por igual es quizás el que ocasiona más conflicto. Sin embargo, este principio se ve reflejado cuando el cuidado y la protección deben ser para todos por igual ante un virus que puede afectar la vida de cualquier persona, llevando a reflexionar que el bien común y el bien mayor están por encima de todo.

\section{CONCLUSIONES}

La presente investigación lleva a la conclusión de que el personal odontológico debe tomar todas las medidas de protección necesarias para la atención a sus pacientes y que la priorización es lo más importante. Queda a criterio de los propios odontólogos las decisiones que tomen en sus consultas. Sin embargo, se recomienda posponer todos los tratamientos electivos y que no sean de última necesidad, con el objetivo de disminuir la exposición de los pacientes y de los mismos profesionales a un posible contagio y poder así dar una rápida y segura asistencia a aquél que lo necesite de urgencia. Los principios éticos son importantes en esta toma de decisiones y se logra coincidir con los autores previamente estudiados que manteniendo las medidas de higiene extremas recomendadas conjuntamente con el distanciamiento social es la mejor manera de cuidar a los pacientes en la emergencia humanitaria ocasionada por el COVID-19.

\section{REFERENCIAS}

1. Gamio L. The workers who face the greatest coronavirus risk. New York Times. 2020.

2. Elster N, Elliott TC. Distinguishing between law and ethics. J Am Dent Assoc. 2018; 149 (12): 1005-1006. doi: 10.1016/j. adaj.2018.08.018.

3. Camargo FD, Batista AK, Unfer B. Ética e moral: reflexoes de dentistas do servico público. Rev Bioét. 2020; 27 (2): 297-303.

4. Orellana CJE, Guerrero SRN. La bioética desde la perspectiva odontológica. Revista ADM. 2019; 76 (5): 282-286.

5. Naidoo S. Ethical considerations in community oral health. J Dent Educ. 2015; 79 (5 Suppl): S38-S44.

6. Cohen DF, Kurkowski MA, Wilson RJ, Jonke GJ, Patel OR et al. Ethical practice during the COVID-19 pandemic. J Am Dent Assoc. 2020; 151 (5): 377-378.

7. Herazo AB. La ética en el manejo del Covid-19. Dental Tribune. 2020.

8. Coulthard P. Dentistry and coronavirus (COVID-19) - moral decision-making. Br Dent J. 2020; 228 (7): 503-505.

9. Himmelberger LK. What are dentists' ethical obligations regarding the provision of emergency care when they are not available to provide that care? J Am Dent Assoc. 2013; 144 (8): 942-943.

10. Spagnuolo G, De Vito D, Rengo S, Tatullo M. COVID-19 outbreak: an overview on dentistry. Int J Environ Res Public Health. 2020; 17 (6): 2094

11. Bali RK, Chaudhry K. Maxillofacial surgery and COVID-19, The Pandemic!! J Maxillofac Oral Surg. 2020; 1-3: doi: 10.1007/ s12663-020-01361-8

Conflicto de intereses: Los autores declaran no tener conflicto de intereses.

Aspectos éticos: Ninguno.

Financiamiento: No se recibió ningún financiamiento.

Correspondencia:

Mariana Isabel Dos Santos Rodríguez

E-mail: mariana2sr@gmail.com 